\title{
Ocorrência de Molossops \\ brachymeles mastivus Thomas, 1911, no Brasil (Chiroptera, Molossidae)
}

\author{
Wilson Uieda (') \\ Valdir Antonio Taddei $\left({ }^{2}\right)$
}

\begin{abstract}
Resumo
A presente nota registra a presença do morcego de cauda livre, Molossops brachymeles mastivus no norte do Brasil. O morcego, um macho adulto, foi capturado numa palmeira de "buriti" (Mauritia sp.) em Manaus, Amazonas. As mediçōes sāo dadas e comparadas com as de machos adultos de Molossops brachymeles cerastes do sudeste brasileiro. Este trabalho é aparentemente o primeiro registro de $\mathbf{M}$. brachymeles mastivus após a descrição original.
\end{abstract}

Atualmente, para a espécie Molossops brachymeles (Peters, 1865) são reconhecidas três subespécies : M.b. brachymeles (Peters, 1865), M.b. cerastes (Thomas, 1901) e M.b. mastivus Thomas, 1911 (Cabrera, 1957; Taddei et al., 1976). Sobre a sua distribuição geográfica pouco se sabe, sendo M.b. brachymeles registrada para o Peru e a Bolívia; M.b. cerastes, para o Paraguai, norte da Argentina e sul e sudeste do Brasil; e M.b. mastivus, apenas para a Guiana (Taddei et al., 1976).

Thomas (1911) descreveu Molossops mastivus (= M.b. mastivus) baseado em um único exemplar, macho adulto, coletado em Guiana. $\mathrm{O}$ autor citado considerou mastivus como a maior forma do gênero, visivelmente maior que M.b. brachymeles e M.b. cerastes. Não conhecemos nenhum registro adicional de M.b. mastivus, desde a descrição original .

Através de Nélio Noberto dos Reis, tivemos a oportunidade de examinar um exemplar macho adulto de Molossops brachymeles mastivus, coletado em julho de 1977 no Bairro do Coroado, Manaus, Amazonas, Brasil $\left(03^{\circ} 07^{\prime} \mathrm{S}, 60^{\circ} 02^{\prime} \mathrm{W}\right)$. A coleta foi feita em foIhas de buriti (Mauritia sp.). O exemplar, preservado em álcool, foi depositado na coleção do Departamento de Zoologia do Instituto de Biociências, Letras e Ciências Exatas de São José do Rio Preto, Universidade Estadual Paulista "Júlio de Mesquita Filho" (DZSJRP 11600).

As medidas externas e cranianas (em $\mathrm{mm}$ ), tomadas segundo os critérios de Vizotto \& Taddei (1973), são as seguintes : cabeça e corpo, 86,0; cauda, 44,0; altura da orelha, 17,3; altura do trago, 4,0; antebraço, 49,0; polegar, 5,2 ; III ${ }^{\circ}$ metacarpo, 47,7; $1 .^{\circ}$ falange, 21,$4 ; 2 .^{\circ}$ falange, 17,8; IV ${ }^{\circ}$ metacarpo, 46,4; $1 .^{\circ}$ falange, $17.6 ; 28^{\circ}$ falange, 4,$5 ; V^{\circ}$ metacarpo, 26,$8 ; 1 .^{\circ}$ falange, 12,$9 ; 20^{\circ}$ falange, 4,4 ; comprimento total do crânio, 24.2; comb. côndilo-canino, 22,1; comp. côndilo-basal, 22,7; comp. basal, 19,8; comp. palatal, 9,6; comp. da série de dentes superiores, 8,9 ; comp. da série de dentes inferiores, 10,2; comp. da mandíbula, 18,2; largura externa dos cingula-caninos, 78 ; largura externa dos molares, 11,1; larg. pós-orbitária, 5,7; larg. zigomática, 17,3; larg. da caixa craniana, 11,5; larg. mastóidea, 18,0; altura da caixa craniana, 7,6.

O nosso exemplar é pouco maior que o descrito por Thomas (1911), com exceção do III ${ }^{\circ}$ metacarpo que no espécime-tipo mediu $49,0 \mathrm{~mm}$. Quando comparado com machos adultos de M.b. cerastes, do sudeste brasileiro, o nosso espécime se mostra maior, em todos os caracteres cranianos e em quase todos os externos, (para comparação vela Taddei et al., 1976). Quando se examina o animal, estando as suas asas estendidas, tem-se a nítida impressão de $M . b$. mastivus possuir as asas mais curtas que M.b. cerastes. Isto é devido ao fato de os dedos serem semelhantes, em comprimento, aos de cerastes. Contudo, o morcego estudado apresenta a cabeça maior e

(1) - Bolsista do CNPq. Departamento de Zoologia da Universidade Estadual de Campinas, SP. (2) - Departamento de Zoologia, Universidade Estadual Paulista - São José do Rio Preto, SP. 
mais larga, o corpo mais robusto e o crânio com o rosto mais alto (Fig. $1 \mathrm{~A}$ e B). Também a forma da abertura da cavidade nasal $e$ a dos incisivos, em vista frontal, são diferentes em M.b. mastivus e M.b. cerastes (Fig. $2 \mathrm{~A}$ e B). Thomas (1911) comentou que os caninos de mastivus são maiores e mais robustos que os de cerastes, fato que também pode ser observado no nosso exemplar. Por outro lado, M.b. cerastes possui a bula timpânica proporcionalmente maior. Outras diferenças podem ainda ser percebidas, porém pela ausência de mais material, não foram feitas maiores considerações.
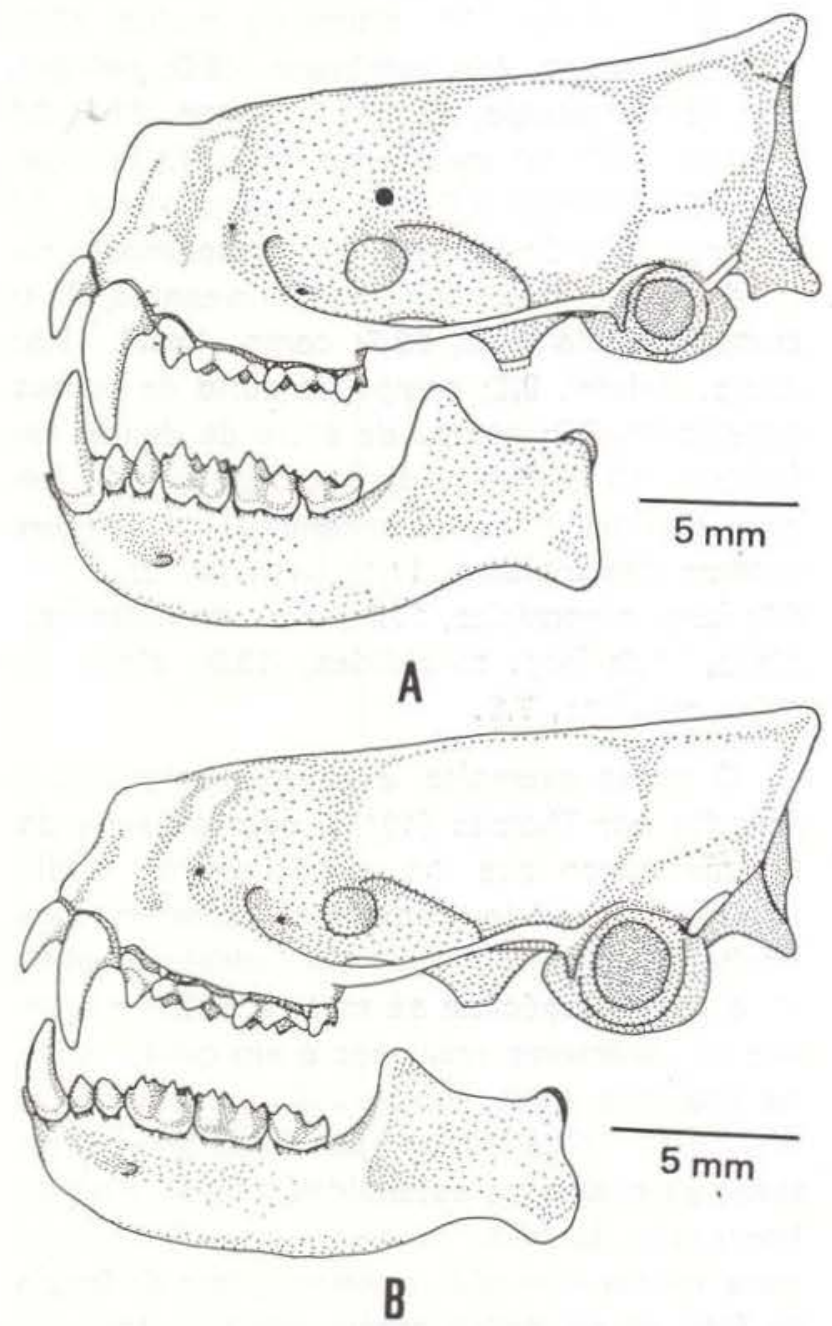

Fig. 1 - Vista lateral do crânio de Molossops brachymeles mastivus (A) e de Molossops brachymeles cerastes (B). As diferenças observadas entre os crânios são comentadas no texto.
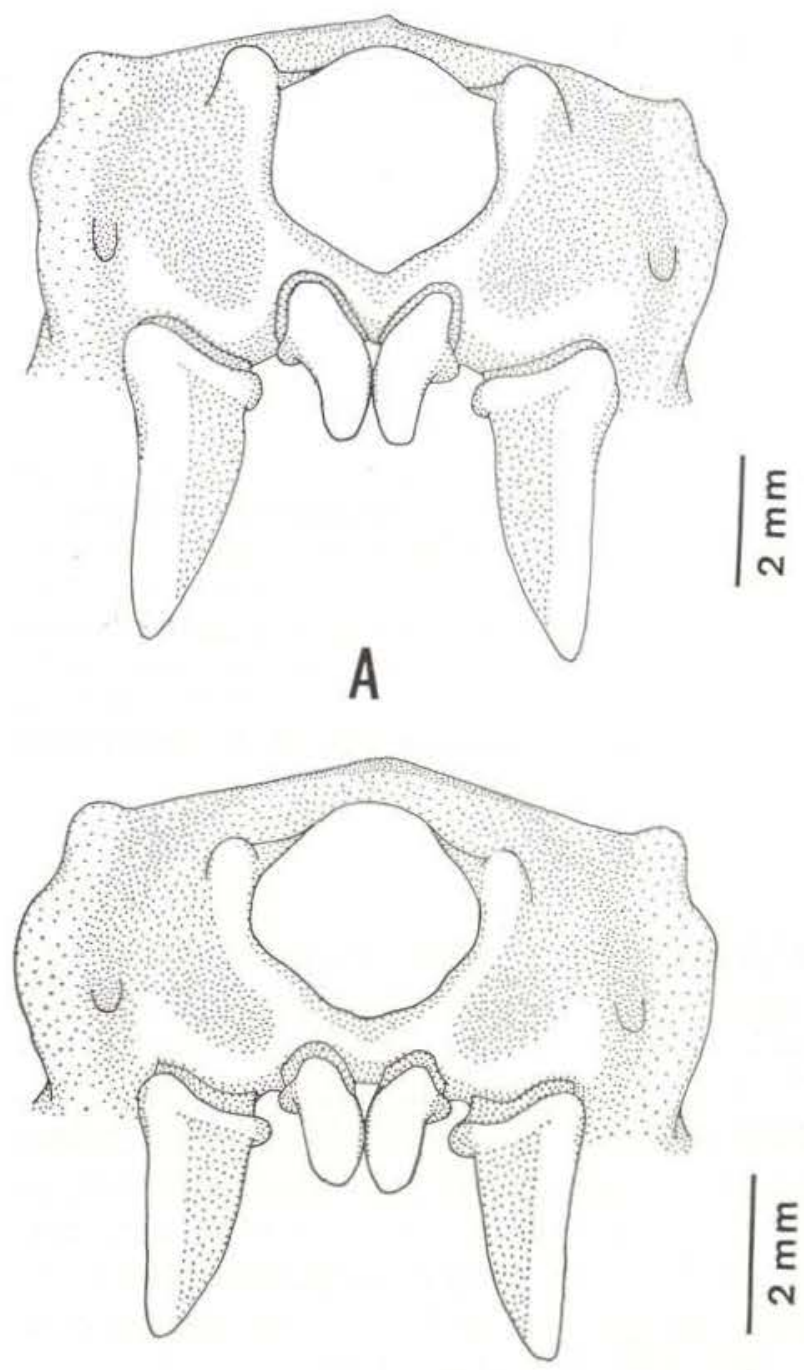

B

Fig. 2 - Vista frontal do crânio, sem a mandibula, de Molossops brachymeles mastivus (A) e de Molossops brachymeles cerastes (B). Notar a forma da abertura da cavidade nasal, a das incisivos e o tamanho dos caninos.

A aparente ausência de M.b. mastivus nas coleções pode muito bem estar relacionada aos seus hábitos e abrigos. Os molossídeos, de um modo geral, voam alto e rapidamente (Vaughan, 1970), fato que torna pouco eficientes as coletas com redes de espera ("mist nets"). Assim sendo, torna-se necessário o conhecimento de seus locais de abrigo. Segundo Dalquest \& Walton (1970) os morcegos do gênero Molossops são fitófilos. Vizotto \& Taddei (1976) consideraram M.t. temminckii e M. planirostris como sendo fitófilos e antropó- 
filos. M. brachymeles cerastes foi classificado como antropófilo por Taddei et al. (1976). Praticamente nada se sabe sobre a biologia da espécie M. brachymeles, com exceção de M.b. cerastes, estudada por Taddei et al. (1976), no sudeste brasileiro.

Pine et al. (1970) citaram a ocorrência de $M$. brachymeles no nordeste de Mato Grosso (Brasil central). Entretanto, os autores mencionados não estabeleceram a posição subespecífica do material, que pela localização geográfica, poderia tanto ser M.b. brachymeles, como M.b. mastivus. O exemplar de M. bra. chymeles citado por Lima (1926), proveniente de São Paulo, deve ser cerastes, pois, além da procedência, os caracteres analisados concordam relativamente bem com esta subespécie. O comprimento do antebraço $(49,0 \mathrm{~mm})$ dado por Lima (1926), sendo bem maior que o máximo $(46,0 \mathrm{~mm})$ assinalado por Taddei et al. (1976), poderia tanto ser um erro de impressão tipográfica ,como de transcrição.

Handley (1976) relacionou dois espécimes de Molossops abrasus da Venezuela, porém não fez referência à posição subespecífica dos mesmos (para o uso de $M$. abrasus ao invés de $M$. brachymeles, veja Husson, 1962).

É necessária a análise de material adicional das três subespécies de Molossops brachymeles e um melhor conhecimento de sua distribuição geográfica, para poder definir meIhor a que nível (subespecífico ou específico), poderia pertencer $M . b$. mastivus. Neste trabalho usamos a nomenclatura corrente. A re. visão do gênero Molossops, que está sendo feita por R.L. Peterson, do Royal Ontario Mu seum, poderá trazer várias modificações na sua composição. Uma delas, poderá ser a volta de Molossops brachymeles mastivus para o nivel específico, como havia sido proposto por Thomas (1911).

\section{Agradecimentos}

Agradecemos ao Dr. Fernando D. de Ávile Pires pela leitura do manuscrito e a Ivan Sazima pelo auxilio na elaboração e revisão deste trabalho. Somos gratos a Nélio R. dos Reis pela oportunidade de estudar o exemplar.

\section{SUMMARY}

The present note records the free-tailed bat. Molossops brachymeles mastivus, in northern Brazil. The bat, an adult male, was captured in a "buriti" palm (Mauritia sp.) in Manaus( Amazonas, Brazil. Measurements are given and compared to those of adult male specimens of Molossops brachymeles cerastes, from southeastern Brazil. Apparently, this paper is the first record of $\mathbf{M}$. brachymeles mastivus since the original description.

\section{BIBLIOGRAFIA}

CABrera, ANGel.

1957 - Catalogo de los mamiferos de America del Sur. Rev. Mus. Argent. Cienc. Nat. "Bernadino Rivadaria". cienc zool., 4 (1): 1-307.

Dalquest, Walter W. \& Walton, Dan W.

1970 - Diurnal retreats of bats. in: Slaughter, Bob H. \& Walton, Dan W. (eds.), About bats. Dallas, Southern Methodist University Press, pp. 162-187.

Handley, Charles O., Jr.

1976 - Mammals of the Smithsonian Venezuelan Project. Brigham Young Univ. Sci. Bull., biol. ser., 20: 1-91

Husson, A.M.

1962 - The bats of Suriname. Zool. Verhand., 58: 1-282.

LIMA, Joño L.

1926 - Os morcegos da colleção do Museu Paulista. Rev. Mus. Paul., S. Pauls, 14: 42-127.

Pine, Ronald H.; Bishop, iain R. \& Jackson, RUth L. 1970 - Preliminary list of mammals of the Xavantina/Cachimbo expedition (Central Brazil). Trans. Royal Soc. Trop. Med. Hyg., 64 (5): $668-670$

Taddei, Valdir A.; Vizotto, Luiz D. \& Martins, SONIA M

1976 - Notas taxionômicas e biológicas sobre Molossops brachymeles cerastes (Thomas, 1901) (Chiroptera-Molossidae). Naturalia, 2: 61-69.

THOMAS, OLDFIELD

1911 - Three new South-American mammals. Ann. Mag. Nat. Hist., ser. 8, 7: 113-115

VAUghan, TERry A.

1970 - Flight patterns and aerodynamics. in: Wimsatt, William A. (ed.), Biology of bats. vol. 1, New York, Academic Press, pp. 195-216.

Vizotto, Luiz D. \& TADDEI, VAldiR A.

1973 - Chave para determinação de quirópteros brasileiros. Fac. Fil. Ciênc. Letr. S.J.R. Preto. Bol. Ciênc., 1: 1-72.

1976 - Notas sobre Molossops temminckii temminckii e Molossops planirostris (ChiropteraMolossidae). Naturalia, 2: 47-59.

(Aceito para publicação em $9 / 11 / 79$ ) 